\title{
Propostas marxistas de educação estética: aproximações e afastamentos em torno do fenômeno da catarse
}

\author{
Vitor Marcel Schühli*
}

Joáo Henrique Rossler

\section{Resumo}

O presente trabalho buscou refletir sobre o papel da educação estética na formação do indivíduo, a partir de teorias que apostam na possibilidade de a arte impulsionar a transformação sobre a realidade e contribuir para a superaçâo da alienação. Foram analisadas as teorias de educação estética dos autores marxistas L. G. Iuldáchev, B. M. Teplov, e A. Sánchez Vázquez. No recorte aqui proposto, buscou-se demonstrar que, apesar de os três autores partirem de uma concepção histórico-social de individualidade, suas formulaçóes diferem no que diz respeito à abordagem do fenômeno da catarse. Na dialética entre identificação e distanciamento do sujeito com o objeto artístico, a ênfase dos autores sobre um ou outro momento da relação acaba por marcar sua posição em torno do fenômeno da catarse. Enquanto em Iuldachév e em Teplov pode-se dizer que encontra destaque o momento da identificação, Sánchez Vázquez busca com o conceito de situação estética recuperar a importância do distanciamento nessa relação. Acredita-se que estudar as formulaçôes desses teóricos pode iluminar as reflexōes atuais sobre a educação estética, bem como auxiliar, com sua perspectiva materialista e dialética, a crítica aos estudos que absolutizam o papel da consciência no projeto de transformação social.

Palavras-chave: Educação Estética. Marxismo. Catarse.

* Mestre em psicologia pela Universidade Federal do Paraná. Professor dos Cursos de Especialização na área da Saúde do ITECNE.

** Doutor em educação escolar pela Universidade Estadual Paulista Júlio de Mesquita Filho. Professor adjunto do Departamento de Psicologia da Universidade Federal do Paraná. 
Os questionamentos sobre o papel da arte na formação humana bem como sobre a importância da educação estética não são recentes e não se afinam em torno a um mesmo projeto. Já no século XIX, Friederich Schiller, no auge do Romantismo alemão, propunha enfrentar os efeitos negativos da oposição entre o racionalismo na sociedade capitalista e as exigências da arte, por meio de uma "educação estética da humanidade" (MÉSZAROS, 2006, p. 173). Para Schiller, a educação estética seria um antídoto necessário à progressiva tendência de alienação desumanizadora, uma saída idealista para a questão, que partia do mero apelo educacional restrito à consciência dos indivíduos e que acabou condenada "a permanecer para sempre no reino das utopias educacionais irrealizáveis” (MÉSZAROS, 2008, p. 81).

Com as contribuições do filósofo alemão Karl Marx, sistematizando o profundo impacto da alienação na criação artística e no gozo estético - a partir dos Manuscritos de 1844 (MARX, 2006) e no restante de sua obra -, surge uma série de propostas que buscam aliar arte e revolução na práxis artística, as quais se desenvolvem no decorrer do século XX, no bojo dos processos revolucionários postos em ação pela classe trabalhadora. Ao contrário do proposto por Schiller (2002), esses movimentos, de forma geral, acreditavam que a consciência reflete as formas objetivas e sociais de alienação do mundo real, advindas em última instância das relações de produção. Assim, buscavam a superação da alienação na arte, o que somente seria possível pela negação e superação da realidade material que determina as formas de alienação da consciência. Conjugavam a transformação da individualidade com processos reais de transformação das relaçóes sociais.

A partir dessas experiências, constitui-se historicamente um conjunto de propostas, baseadas no materialismo histórico e dialético, o qual inclui a arte na luta pela emancipação humana e por uma individualidade que possa se autodeterminar de maneira livre e consciente. Atualmente, seja por ajustes sociais, políticos e econômicos, seja por açóes ideológicas, as individualidades são premidas a subordinar-se aos interesses do sistema em crise. Assim, verifica-se um refluxo do movimento revolucionário da classe trabalhadora e o consequente abandono do projeto de emancipação humana a partir da década de 80 do século XX (MORAES; JIMENEZ, 2009). Determinado por esse contexto, reflui também o movimento teórico que defende a arte e sua contribuição formativa no projeto da emancipação humana. 
Na tradição teórica marxista, a arte é entendida como uma objetivação de nível superior (uma objetivação genérica para-si), por significar uma possibilidade de elevação para além da espontaneidade e alienação da vida cotidiana; que pode colocar o ser humano numa relação mais próxima com o gênero, contribuindo para a formação de uma individualidade mais livre e consciente. Como define Duarte (1993), uma individualidade parasi. Entretanto, como a inspiração artística não poderia vir de outro lugar senão das relaçóes reais entre os homens, seu conteúdo está perpassado pelas contradiçóes da sociabilidade concreta em que se desenvolve. $\mathrm{Ou}$ seja, é marcado pelos processos objetivos e subjetivos de alienação e dominação que ainda hoje imperam nas relações sociais. Situadas nessas condiçóes, as potencialidades desalienantes da práxis artística não estão de todo sufocadas, mas sim impedidas de se efetivarem nas grandes massas da sociedade capitalista. E esse talvez possa ser considerado o nó górdio das propostas de superação do capitalismo no campo da arte: a socialização do patrimônio cultural e, em especial, da arte para as massas, pois, juntamente com o desenvolvimento das forças produtivas, e sem tirar a importância do desenvolvimento econômico - que é uma condição para o estabelecimento de relações mais livres em relação à natureza -, é preciso desenvolver também a cultura, gerar novas necessidades, enriquecer as individualidades pela produção de carecimentos de tipo superior. É necessário também desenvolver uma relação mais consciente com o mundo, o que só se faz com as apropriações das objetivações mais desenvolvidas do gênero humano.

As experiências socialistas e as teorizaçóes a seu respeito tentaram responder a essa questão de diferentes maneiras, nenhuma delas consensual. Desde os primeiros decretos de Lenin sobre a nacionalização de galerias ou coleções de arte logo após a revolução soviética, de outubro de 1917 (LENIN, 1979, p. 295), até o decreto de reconstrução das organizaçóes literárias e artísticas de Stalin, em 1932 (SÁNCHEZ VÁZQUEZ, 1996a) - que foi decisivo para a adoção do Realismo Socialista como doutrina oficial e que é comumente citado como uma forma de dogmatismo que influenciaria a criatividade e o gozo estético -, todos tinham em comum a defesa da socialização da arte e o desenvolvimento das potencialidades humanas para a formação do novo homem.

Assim, nas experiências revolucionárias, tentou-se aliar, de diferentes maneiras, arte e revolução. Ou seja, buscou-se contribuir com 
o desenvolvimento de uma nova sociedade e de uma individualidade mais rica, por intermédio do desenvolvimento de uma educação estética que, somando-se à educação em geral, contribuísse com o processo de apropriação das objetivaçóes para-si. Buscou-se, também, o desenvolvimento de uma arte "desalienadora", que contribuísse para um maior conhecimento e entendimento do real, mas também que impulsionasse a ação transformadora sobre a realidade.

De fato, em diversos momentos históricos, a arte foi chamada à construção de projetos revolucionários de sociedade ou acionada como instrumento na manutenção da ordem vigente. Como é o caso de Pushkin, quando chamado a defender com sua obra o czarismo (PLEKHÁNOV, 1977).

Se atualmente parece não existir divergência quanto à influência da estética e, mais especificamente, da arte na formação dos indivíduos, é certo, também, que as discordâncias continuam versando em torno de um entendimento materialista ou idealista na relação da arte com o mundo e com a consciência humana. Várias das propostas atuais de educação artística e estética trazem, por exemplo, marcas dos ideais da educação moral de Kant ou do subjetivismo da educação estética de Schiller. Sem contar ainda que, no campo educacional, o debate hoje se perde, polarizando esses mesmos termos: "educação estética" e "educação artística". A educação artística, estando ligada ao fazer arte, à produção de objetos de arte, e a educação estética à apreciação e fruição das obras de arte (CASTANHO, 2005). ${ }^{1}$

Nesse trabalho, considera-se que a separação entre educação estética e educação artística, nos termos pontuados acima, proporia uma separação artificial entre objetivação e apropriação. Pelo texto de Teplov (1991), o qual será discutido adiante, é possível compreender como os dois termos estão intrinsecamente ligados, sendo a educação estética uma condição para a educação artística. Quando o sujeito se objetiva na educação artística, o faz mediado pelas possibilidades postas pela educação estética que obteve.

Por essa pequena contribuição, já é possível perceber que as propostas de educação estética de fundamentação marxista podem iluminar as reflexôes contemporâneas sobre o papel da educação estética na formação do indivíduo, o que justifica sua retomada. Optou-se por apresentar propostas ainda pouco estudadas e difundidas e que, acredita-se, podem contribuir para o avanço da pedagogia teórica e da psicologia da arte. 
Dadas as limitaçóes deste artigo, buscar-se-á trazer à tona alguns dos elementos principais presentes nas concepçóes de educação estética de três autores marxistas, sinalizando a riqueza de suas concepçóes e contribuiçóes para as reflexões educacionais e psicológicas contemporâneas. São eles: L. G. Iuldáchev, B. M. Teplov² e A. Sánchez Vázquez. O recorte aqui proposto privilegia ainda a análise das aproximaçóes e afastamentos das concepçóes desses autores quanto ao conceito de catarse. ${ }^{3}$

$\mathrm{Na}$ educação estética, a catarse aparece como fundamental para a apreensão da obra e desenvolvimento da sensibilidade. Embora nem sempre com esse nome, o uso do termo e de seus correlatos (rendimento, experiência de êxtase estético) procura reforçar o momento de identificação, ${ }^{4}$ entrega e rendimento emotivo como momento importante para a atividade educativa. Momento esse que figura como um desafio para o educador, que deve desenvolver a avaliação dos critérios objetivos da obra, porém sem deixar de produzir nos educandos uma relação emotiva e sensível com ela.

Esse processo de identificação do sujeito com a obra de arte é tematizado desde Aristóteles, chegando a seu ápice com o naturalismo do final do século XIX e início do século XX, que buscava a identificação do espectador com o herói como forma de universalização dos valores burgueses. Sánchez Vázquez (1999) estabelece uma diferenciação entre identificação e fusão. A primeira seria um processo necessário de vinculação e relação entre sujeito e objeto, e a segunda representaria a total anulação do sujeito no objeto, característica das estéticas idealistas que não defendem a objetividade da obra de arte.

Buscando superar as estéticas idealistas e combater os estudos que absolutizam o papel da consciência no projeto de transformação social, é que a concepção materialista defendeu, algumas vezes, o processo de identificação como o estabelecimento de relaçóes conscientes para com os objetos e fins destas vinculações, contribuindo para a humanização do indivíduo e para sua formação como individualidade para-si (ROSSLER, 2003, p. 230).

Considerando a importância que ganha a catarse como problemática situada na dialética entre identificação e distanciamento na relação entre sujeito e objeto artístico, é que esse trabalho investiga a importância que ganha o fenômeno nas teorias sobre educação estética marxista. Refletir sobre a importância da educação estética para a formação do indivíduo e sobre a transmissão de valores cognoscitivos, morais e emocionais por intermédio 
da arte nessa perspectiva consiste numa tarefa importante para estabelecer uma crítica vigorosa às concepçóes que absolutizam o papel da consciência no projeto de transformaçáo, ou ainda, que propóem o retorno aos ideais subjetivistas da educação estética de Schiller.

\section{Proposta de educação estética na União das Repúblicas Socialistas Soviéticas (URSS): L. G. Iuldáchev e a educação estética dos trabalhadores}

Apesar da diversidade de posiçóes que conviveram durante o processo de formação e desenvolvimento da URSS no campo da estética, optou-se por analisar aqui a concepção de educação estética de L. G. Iuldáchev (1982), em seu subcapítulo sobre "A educação estética dos trabalhadores", presente na coletânea "Fundamentos da estética marxista-leninista", publicada em 1978. ${ }^{5}$

Acredita-se ser essa uma posição representativa, que sistematiza um discurso tido como "oficial", tendo sido publicada em um momento em que vários dos debates travados à época da revolução em torno das questóes artísticas já haviam ganhado uma posição relativamente homogênea. Buscando não cristalizar essa posição nem esquecer as posiçóes divergentes, adicionaram-se a essas consideraçôes algumas reflexôes importantes sobre o contexto histórico de desenvolvimento da arte e das concepçóes estéticas soviéticas, bem como uma reflexão sobre o papel que, acredita-se, desempenhou a concepção da catarse na arte em sua relação com o realismo socialista.

Na posição de Iuldáchev, a educação estética aparece como parte da educação comunista dos trabalhadores, com o objetivo de modelar a personalidade harmoniosa e multifacetadamente desenvolvida (o que também aparece como "o homem perfeito e sublime"). Seu objetivo imediato seria a formação dos sentidos, necessidades, interesses, gostos, ideais estéticos dos trabalhadores; sua capacidade de criação artística e da consciência estética em geral. Não há dicotomia, portanto, entre educação estética e educação artística na formação da consciência estética dos trabalhadores.

Subjacente a essa posição estaria a elevação da eficiência do trabalho ideológico ${ }^{6}$ do partido, ou seja, a educação comunista das massas trabalhadoras. O objetivo final da educação estética não é, então, a formação de uma consciência estética, mas a educação da consciência 
comunista, o que só ocorreria pela unidade indissolúvel de todos os tipos de educação.

Pensar a educação estética em termos de aumento da eficiência do trabalho ideológico do partido é uma posição que comumente desperta inúmeras críticas. No campo da arte, deixar que alguma outra função (moral, emocional, cognitiva etc.) adquira mais importância do que a função estética significa privá-la de sua função essencial, descaracterizando-a inclusive como arte. Todavia, não se pode perder de vista que se tratava de um momento histórico único: um país com condiçôes culturais atrasadas, no qual a socialização da cultura precisava ocorrer de forma rápida à custa de minar o projeto de uma sociedade livre da alienação.

O que se quer destacar aqui é a ambição dessa proposta, que busca o que seria impossível sob as relaçóes de dominação do sistema capitalista: o desenvolvimento multilateral dos indivíduos, dando para isso posição de destaque para a educação estética.

Já no programa do Partido Comunista Soviético encontrava-se a preocupação com a criação das condiçóes para a revelação mais plena das capacidades pessoais de cada indivíduo, com a educação estética de todos os trabalhadores e com a formação de elevados gostos artísticos e hábitos culturais. Concebe-se uma direção para o desenvolvimento do indivíduo baseada na sua formação como indivíduo desenvolvido harmoniosa e multilateralmente, com consciência comunista e diversas capacidades.

Ainda influenciada pela concepção do belo, abundam na posição de Iuldáchev (1982) termos como "homem belo", "perfeito", "sublime" e "positivo". Trata-se, na verdade, do que em outros textos aparecerá como a "formação do novo homem", que pressupóe a combinação harmônica, a conformidade entre a beleza humana (sobretudo dos atos, açôes e comportamentos) e a riqueza do seu mundo espiritual (entendida como o sentimento e a vontade canalizados para o bem de todos os trabalhadores e para a edificação do comunismo) (IULDÁCHEV, 1982).

Para que o desenvolvimento das capacidades humanas ocorra, entretanto, o autor considera que é necessário dispor de tempo livre para os prazeres e para o ócio, ou seja, é necessária a redução do tempo de trabalho necessário e a utilização mais racional dos tempos livres (IULDÁCHEV, 1982). Cumprida essa condição, é preciso ainda considerar que as riquezas 
da cultura não possuem por si próprias ação orientadora, necessitando de orientação sistemática e consequente, norteada pelo belo na arte e na realidade.

O papel da estética marxista-leninista seria o de lançar as diretrizes que devem ser tomadas como alicerces metodológicos para o desenvolvimento das teorias pedagógicas de educação estética. Nessa direção, a educação estética deveria orientar-se para os três meios nos quais a consciência estética pode desenvolver-se: a) o meio social de trabalho e a vida cotidiana, que deve ser organizado esteticamente e com forma estética; b) os fenômenos estéticos da natureza e da sociedade; c) a arte - mais à frente ver-se-á que Sánchez Vázquez (1996c) propóe uma divisão do estético em esferas muito parecidas com essa.

Nos três meios citados, a apropriação estética deve ocorrer de forma orientada (intencionalmente produzida), por náo se dar somente pelo contato com o ambiente e com os objetos esteticizados. Essa orientação deveria considerar a experiência de vida de cada indivíduo e o nível de desenvolvimento de seus sentidos sociais e do seu pensamento. Nessa proposta, o processo de formação da consciência e da atitude estética do ser humano perante a realidade é tomado como um processo de conhecimento do mundo, que vai da contemplação viva ao pensamento abstrato, e deste à prática (atividade estética incluindo a criação artística).

Nesse processo de conhecimento do mundo mediado pela consciência estética - no qual a educação estética ajudaria a organizar o contato com os fenômenos estéticos da realidade, esclareceria o que foi percebido e organizaria a atividade estética, incluindo a criação artística - Iuldáchev (1982) atribui especial atenção à formação das crianças, posto que estas não teriam ainda seus sentidos sociais formados, não sendo capazes de perceber plenamente a arte. A educação estética constituiria, então, a etapa inicial, mas de importância crucial na formação da consciência estética das pessoas, sendo essa a etapa de desenvolvimento dos fundamentos para um indivíduo desenvolvido harmoniosa e multilateralmente.

Diversos autores marxistas no campo da estética concordarão com a proposta de um desenvolvimento multifacetado (omnilateral) da personalidade, com o estabelecimento das tarefas de formação de uma consciência artística para além do contato com a arte e com o entendimento do estabelecimento da consciência estética como um processo de 
conhecimento do mundo. No entanto, há divergências nesse campo no que tange à influência do partido nas definiçóes de juízo estético, o que chegou a influenciar as formas de produção artística, consagrando o realismo socialista como forma a ser valorizada. Isso teria tendenciado também a educação estética, que se desenvolveu baseada nessa forma artística, prejudicando a apreensão de outras, bem como o desenvolvimento multilateral que se buscava.

Não se pode esquecer, entretanto, que antes da consagração do realismo socialista como forma oficial, muito se discutiu na URSS sobre o estabelecimento de uma cultura proletária ou sobre a incorporação e superação da cultura burguesa, incluindo a socialização dos bens culturais. Também muito se desenvolveu artisticamente durante as vanguardas, a despeito do grande atraso econômico e cultural a que o país estava submetido.

As difíceis condições de vida de camponeses e operários, deve-se assinalar, foi o que estimulou o aparecimento de um importante grupo de escritores que utilizavam o realismo como arma de denúncia e crítica social. $\mathrm{O}$ sofrimento humano e a crítica às posições burguesas geradoras desse sofrimento aparecem retratados nessas produçóes (vide os heróis camponeses de Gorki e Pushkin). Essa visão crítica que desenvolvia o realismo, somada à sua aceitação pelas massas (que nem sempre compreendia as formas artísticas desenvolvidas pelas vanguardas) criou o solo para a adoção do realismo como forma oficial de expressão artística.

A produção artística passa a valorizar as massas e as posiçóes da classe trabalhadora, representando um herói aliado à posição revolucionária. Muitas das produçóes desse período acabaram rendendo-se à imposição dessa forma sem, contudo, expressar a partir dela a riqueza de uma situação particular que ligasse o ser humano à máxima esfera de desenvolvimento da humanidade. A prova disso é que poucas delas conseguiram resistir ao tempo e ser tomadas como clássicos da produção artística humana.

Nas palavras de Sánchez Vázquez ao descrever as posiçôes de Lunacharsky durante esse processo:

O grave problema de conseguir o encontro entre a arte e as massas, que tanto o havia preocupado nos primeiros anos da revoluçáo, parecia ter encontrado sua solução desde a década de 1930, com uma arte supostamente 
realista e socialista que alcançava uma compreensão maciça. Mas certamente a solução encontrada a custo de um rebaixamento e uma simplificação das formas de expressão, implicava uma mudança nos termos da relação. Com efeito, não era essa a arte que Lunacharsky havia buscado, nem eram essas massas - educadas em um culto acadêmico às velhas formas burguesas de expressáo - as que ele, por um caminho complexo e contraditório, havia pretendido buscar. (SÁNCHEZ VÁZQUEZ, 1996a, p. 168).

Nesse "culto acadêmico" a uma forma, considera-se aqui que a identificação do espectador com o herói tinha papel fundamental para mobilizar as massas no sentido da construção da política oficial. A defesa do realismo socialista leva a pensar na identificação com o herói realista como forma de vivência da realidade estética e construção de valores no indivíduo, bem como de incentivo à sua atuação no mundo mediado por esses valores. Nessa posição, poder-se-ia falar, então, de uma defesa da catarse como mecanismo de identificação com o herói e construção de valores, de uma vivência subjetiva que aproxima o sujeito do herói retratado na obra artística. É na dialética entre as propostas de identificação e/ou distanciamento que se situa, na sequência, o tema da catarse.

\section{Proposta de educação estética em Sánchez Vázquez: a catarse como fusão?}

O início do pensamento estético do filósofo mexicano Sánchez Vázquez encontra-se profundamente marcado pela trajetória da Revolução Cubana. Já em suas primeiras publicaçóes sobre o tema, a partir do final da década de 1950, apresentava a arte como uma forma de práxis ou trabalho criador, visando a sustentar uma critica aberta à teoria da arte como reflexo que, no seu entendimento, ajudaria a elevar uma forma de prática, supostamente realista, à condição de arte por excelência. Considerava a posição soviética do "realismo socialista" reducionista e defendia que essa posição levaria à asfixia da criação artística e à esclerose do pensamento estético, consistindo em uma ideologia no sentido negativo do termo: o de "falsa consciência" (SÁNCHEZ VÁZQUEZ, 1996b, p. 107). Seus textos buscam inspiração na criatividade e na originalidade da Revolução Cubana, que surpreende 
os cânones revolucionários no terreno político e que, esperava o autor, poderia romper também com as práticas dogmáticas e petrificadas que nos países socialistas, em nome do marxismo-leninismo, limitavam a liberdade de criação, decretavam formas e conteúdos e davam respaldo a essa forma oficial de fazer arte e literatura.

Para Sánchez Vázquez (1996b), a crítica marxista da realidade permite fazer frente às estéticas idealistas e irracionalistas, compreendendo os obstáculos que a mercantilização coloca à criatividade humana no campo da estética e da arte em particular. Esse conhecimento permite historicizar o estético e, com isso, mostra a dificuldade de defini-lo, já que suas esferas se desenvolvem de acordo com as épocas históricas. Dada essa dificuldade, Vázquez propóe que se opere com um conceito de mínimo: o indispensável para distinguir o estético de outras formas de comportamento humano - teórico, moral, político, prático-utilitário etc. (SÁNCHEZ VÁZQUEZ, 1996c).

No contexto atual, em que a experiência estética expandiu e universalizou os limites do universo estético, Sánchez Vázquez (1996c) distingue o estético em quatro esferas, assinalando que todas devem ser levadas em conta em um projeto de educação estética. A primeira região fundamental ou esfera seria a arte; a segunda, o estético na natureza; a terceira, o estético técnico; e a quarta, o estético na vida cotidiana.

Com relação à primeira esfera, o autor destaca que é apenas a partir do século XVIII que a função estética se concentra na arte (entendida como arte para ser contemplada nos lugares adequados) e que essa esfera passa a ocupar papel proeminente dentre as outras (SÁNCHEZ VÁZQUEZ, 1996c). A partir desse período, a função estética se torna dominante e passa a integrar nela toda função extraestética.

Se levado em conta que esse é um período recente comparado à história da humanidade, pode-se inclusive supor que a arte possa perder essa centralidade no universo estético. Mas ocorre que ela ainda náo deixou de mostrar sua vitalidade, ao contrário do que previa Hegel (2001) com sua tese sobre a morte da arte. Tese essa, por sinal, que ainda hoje é reafirmada por algumas correntes artísticas que centram sua atenção no cotidiano ou no processo artístico, em detrimento da objetividade da obra.

O lugar proeminente da arte poderia se explicar porque, num contexto em que a criatividade se vê limitada pela crescente alienação 
nas mais diversas atividades humanas, nela e por ela, pode-se satisfazer a necessidade humana de criar e de humanizar a realidade. Isso não significa, entretanto, que o produto artístico transformado em mercadoria não deixe de ser influenciado pelo contexto econômico-social hostil à criatividade (SÁNCHEZ VÁZQUEZ, 1996c, p. 98).

$\mathrm{Na}$ teorização desse autor não se nega que a arte possa cumprir funçóes que não são apenas estéticas (morais, políticas, ideológicas e sociais), mas o cumprimento da função estética aparece como condição para a realização de qualquer outra função (SÁNCHEZ VÁZQUEZ, 1996c). Ou seja, a arte só pode contribuir com a formação da individualidade para-si, na medida em que cumpra sua função estética, entendida como objetos ou processos sensíveis que se tornem significativos. Essa afirmação guarda semelhança com a afirmação de Croce que é corroborada por Gramsci (1978, p.10): “a arte é educativa enquanto arte, mas não enquanto arte educativa, porque neste caso ela é nada e o nada não pode educar”.

A segunda esfera em que o estético se expressaria seria a natureza, quando os objetos naturais expressem uma forma significativa (SÁNCHEZ VÁZQUEZ, 1996c). Apesar de adaptar a natureza a si, o ser humano nem sempre a estetizou. Foi ao longo de sua relação prático-material com a natureza que passou a marcá-la com o signo das paixóes, esperança, nobreza ou serenidade humanas.

A terceira esfera na qual se expressa o estético é a esfera técnica (SÁNCHEZ VÁZQUEZ, 1996c). A mediação que a tecnologia exerce na relação do homem com o mundo não deixou de afetar sua relação com o estético. E, nesse âmbito, ocorreria o oposto do que acontece na esfera da arte. No estético técnico, a função estética é que se encontra subordinada à funcionalidade do objeto. Ou seja, para que o estético se expresse deve ocorrer na forma exigida pela funcionalidade do objeto.

Finalmente, a quarta esfera do estético é composta pelo estético na vida cotidiana - âmbito em que se realiza a maior parte dos atos e atividades humanas (SÁNCHEZ VÁZQUEZ, 1996c). Nessa esfera, os objetos utilizados para satisfazer as necessidades humanas caracterizam-se essencialmente pelo seu valor de uso. Se elementos estéticos são adicionados a esses objetos, superando sua utilidade prática, pode-se falar de um valor estético. Durante séculos essa foi a principal forma de expressão do estético, que se integrava por meio dos objetos artesanais à vida cotidiana. 
A produção de obras de arte à margem da produção de objetos de uso cotidiano só passa a ocorrer com o desenvolvimento da manufatura e da indústria, dando origem à diferenciação entre arte, artesanato e objetos industriais. $\mathrm{O}$ objeto industrial diferencia-se da obra de arte não só porque nele a utilidade se mantém como valor dominante sobre o valor estético, mas também por seu caráter massivo. Diferente da obra de arte única e irrepetível, a qualidade estética do produto industrial é inerente não só a um produto, mas a todos os que realizam e repetem sua forma. Pode-se falar então de uma estética industrial como parte da estética do cotidiano, âmbito no qual o valor estético subordina-se não somente ao valor de uso, mas também ao valor de troca. Sujeito a critérios de rentabilidade, o estético encontra dificuldades para integrar-se à produção industrial.

Assim, o campo do estético nas teorizaçóes de Vázquez está constituído pelo conjunto de objetos, fenômenos ou processos que cumprem uma função estética (SÁNCHEZ VÁZQUEZ, 1996c). Essa função estética pode ser dominante (como ocorre na arte), pode coexistir com outras funçóes (como no artesanato e nos objetos da vida cotidiana), ou pode subordinarse a uma função prático-utilitária (como ocorre na arquitetura, na arte industrial e na estética técnica). Entretanto, o autor não desconsidera que outras atividades que não se produzem com a intenção estética possam gerar efeito estético, como manifestaçóes políticas ou esportivas, ou a própria natureza (SÁNCHEZ VÁZQUEZ, 1996c). Em todos esses casos, os objetos ou processos entram no campo estético - de maneira dominante, secundária, constante ou transitória - por seu caráter sensível e por se tornarem significativos (SÁNCHEZ VÁZQUEZ, 1996c, p. 96).

No que se refere à proposta de educação estética de Adolfo Sánchez Vázquez (1999), pode-se afirmar que não prioriza somente o belo como categoria estética (trabalha além do belo com as categorias de feio, sublime, trágico, cômico e grotesco) e que enfatiza o desenvolvimento da sensibilidade em todas as esferas do estético, embora não desloque a arte da centralidade do universo estético atual. Seu enfoque na estética cotidiana e na produção de objetos usuais industriais deve-se ao reconhecimento de que essa esfera da estética é a mais necessária à vida. E, no entanto, a que mais obstáculos econômicos e sociais encontra para seu desenvolvimento, confirmando que os problemas estéticos não são apenas teóricos, mas práticos, reais (SÁNCHEZ VÁZQUEZ, 1996c). 
Nesse sentido, a educação estética tem a função de desenvolver a consciência estética, em geral, e a consciência artística, em particular, dos indivíduos, tanto no que se refere à sua compreensão e valorização dos objetos estéticos como à atividade que, especialmente no terreno artístico, os leva a produzi-los (SÁNCHEZ VÁZQUEZ, 1996c, p.95). É preciso que a educação estética compreenda as esferas do estético para cumprir sua tarefa primordial de contribuir para elevar a consciência e a atividade estética dos indivíduos, desenvolvendo a sensibilidade estética e aumentando o papel que o comportamento estético desempenha na vida do indivíduo.

É no texto sobre a estética, de José Revueltas, de 1983 (SÁNCHEZ VÁZQUEZ, 1996d), no qual já aparece a reflexão sobre a dialética entre alienação e desalienação, que se encontram algumas reflexóes que permitem tratar a questão da catarse no interior de sua proposta de educação estética.

Sánchez Vázquez (1996d) não deixa de concordar com Revueltas, nessa obra, sobre o elevado papel da arte no processo de desalienação do homem (de reapropriação de si), tanto no presente como no futuro. Embora advirta sobre o perigo de absolutizar o papel da consciência, recordando os neohegelianos que Marx tanto criticou (SÁNCHEZ VÁZQUEZ, 1996d). Todavia, é em "Convite à estética" (SÁNCHEZ VÁZQUEZ, 1999) - obra de 1992, e quiçá a mais madura de suas obras - que irá avançar da análise da relação entre alienação e desalienação em Revueltas, para assim tomá-la como dialética entre identificação e distanciamento.

Adotando a mesma posição de seu texto anterior, nessa obra o autor reafirma a concepção da objetividade da obra de arte, como condição para que possa existir uma relação entre sujeito e objeto (SÁNCHEZ VÁZQUEZ, 1999). No entanto, propóe também o conceito de situação estética, ou seja, a ideia de que sujeito e objeto devam se separar de si mesmos, ou de uma parte do seu ser, para que possam se encontrar nessa situação estética. Essa concepção surge da crítica feita pelo o autor à posição, às vezes defendida, acerca da fusão na arte entre sujeito e objeto.

As teorias de Lipps e Volket passam, a partir do final do século XIX, a explicar a contemplação estética por um processo de "projeção sentimental" (Einfühlung) do sujeito (SÁNCHEZ VÁZQUEZ, 1999). O "empréstimo" de sentimentos do sujeito ao objeto é o que o tornaria expressivo e isso determinaria um processo de fusão ou identificação entre sujeito e objeto, a partir do qual, o objeto adquiriria um tom afetivo ao ser contemplado 
(SÁNCHEZ VÁZQUEZ, 1999). Nessa concepção, o objeto se converte em simples expressão do sujeito, desaparecendo a distância entre eles. A contemplação estética acaba por revelar-se uma autocontemplação, expressando um subjetivismo radical.

Divergindo dessa posição, o autor propóe que o objeto estético tem a realidade própria de um objeto sensível que, por sua forma, tem um significado (SÁNCHEZ VÁZQUEZ, 1999, p. 149). Ainda que necessite das percepçóes individuais para que sua objetividade se exponha, o objeto estético não se dilui nas diferentes projeçôes psíquicas dos observadores. A contemplação estética não é possível mesmo que o objeto exista por si mesmo, ainda que não passe de projeção subjetiva, só existindo na relação peculiar e singular entre sujeito e objeto. Relação na qual um ou outro deixa de ser o que era antes ou fora dela. Essa relação singular caracteriza a situação estética, na qual o sujeito deve colocar entre parênteses suas preocupaçóes pessoais ou seus projetos imediatos para instaurar essa nova realidade; e o objeto, por sua vez, deve desvincular-se do contexto físico, usual que o rodeia ou extrapolar o corpo físico sensível que o sustenta, para alcançar ou encarnar outra realidade: a realidade propriamente estética.

Em lugar da projeção ou identificação sentimental, Sánchez Vázquez (1999) propóe o que Brecht já havia considerado: o distanciamento (Verfremdung). O sujeito, seja ator ou espectador, não deve identificar-se intimamente com o objeto, o personagem no caso. Efeito que Sánchez Vázquez (1999, p. 152) também reconhece nos formalistas russos, quando propunham à arte o papel de elevar a capacidade de surpresa e alheamento frente ao banal e cotidiano. Por esse mecanismo, o sujeito recuperaria sua liberdade, seu poder reflexivo e crítico, encontrando-se na situação estética com uma realidade mais humana do que a que lhe é familiar, do que a de seu cotidiano.

Para além do conceito de identificação como fusão, Vázquez agrega o conceito de distanciamento, pois é preciso uma distância psíquica entre sujeito e objeto para que haja a contemplação estética (SÁNCHEZ VÁZQUEZ, 1999). A arte se distancia então da realidade humana "vivida" (não é a expressão direta da realidade vivida anteriormente pelo artista), mas, ao se distanciar, expressa uma relação do homem com o mundo mais rica, plena e profunda. E esse mundo criado pelo artista, no qual se passa de uma realidade "vivida" a uma realidade humana mais profunda, é o que 
constitui o centro de gravidade do objeto que se oferece à contemplação estética.

Embora Sánchez Vázquez (1999) não utilize explicitamente o conceito de catarse, em sua acepção marxista, fica claro a partir de suas reflexões que, em seu entendimento, o processo ao qual esse conceito se refere não é tomado como fusão, como projeção sentimental. Ao criticar a fusão entre sujeito e objeto está propondo que se entenda essa relação como unidade dialética, ou seja, unidade entre sujeito e objeto, na qual um não se reduz ao outro. Existe nessa proposição uma dialética entre união e separação, entre identificaçấo e distanciamento de sujeito e objeto, que constitui a própria natureza de sua relação na situação estética.

Essa posição implica uma crítica vigorosa às posições idealistas, que negam a objetividade da obra de arte, e também às posições subjetivistas, pois sujeito e objeto teriam realidades próprias. Do ponto de vista da educação estética, as proposiçóes de Sánchez Vázquez (1996c) levam a considerar as diversas esferas do estético, mas o autor é enfático ao defender que a arte ainda desempenha função predominante, de maneira que não se pode confundir sua proposta com as propostas contemporâneas que defendem a esteticização do cotidiano, diminuindo a participação da arte na formação da individualidade e propalando seu fim.

\section{Proposta de educação estética de B. M. Teplov: a catarse como rendimento?}

Boris Mikhailovich Teplov (1896-1965) foi um psicólogo russo que trabalhou em diversos institutos do exército e, a partir de 1929, no Instituto de Psicologia, até então vinculado à Universidade de Moscou. Seus estudos mais conhecidos tratam das diferenças individuais no que se refere às capacidades e talentos, e sua tese de doutorado tratava da Psicologia das capacidades musicais (SHUARE, 1990).

Sua teorização sobre as capacidades individuais não desconsidera o homem em sua dimensão biológica, mas destaca o desenvolvimento de capacidades e necessidades humanas, bem como o papel da educação e do ensino nesse processo (SHUARE, 1990).

Para esse trabalho, interessa-nos analisar seu texto de 1946 sobre os "Aspectos psicológicos da educação artística" (TEPLOV, 1991), no qual 
Teplov utiliza fragmentos e ideias de vários autores para construir seu ponto de vista, dando testemunho do que afirma Shuare (1990) sobre sua elevadíssima cultura científica, estética e filosófica.

O texto de Teplov (1991) é dirigido à discussão sobre a atividade artística na infância e aponta para a necessidade da educação estética para todas as crianças e para as capacidades que nesse processo são desenvolvidas. Defende que a atividade artística não é apenas o cenário para a manifestação das capacidades humanas, mas que as capacidades se formam e se desenvolvem durante a atividade.

Essa tese leva-o à defesa da inclusão de atividades produtivas na educação e não somente de atividades artísticas reprodutoras. Por acreditar que a atividade artística criativa está reservada aos especialmente dotados, a prática educativa tradicional, em geral, exclui essas atividades da educação da maioria, privando-os do desenvolvimento de uma personalidade plena. Dificilmente as práticas tradicionais combinam, por exemplo, a execução de instrumentos e leitura de partituras (atividade reprodutora) à atividade de composição musical (atividade criativa).

Teplov (1991) situa a arte como um produto de todos os esforços e de todas as capacidades do homem, tendo um efeito profundo e de grande alcance nos diversos aspectos da psicologia humana. Não somente sobre a imaginação e os sentidos, mas também sobre o pensamento e a vontade. Considera a educação artística como sendo um dos mais poderosos meios para desenvolver uma personalidade plena e harmoniosa, sendo importante para o desenvolvimento da consciência e da autoconsciência, para a educação moral e a formação da concepção de vida (TEPLOV, 1991).

Embora as capacidades humanas, de modo geral, desenvolvam-se com base em requisitos prévios da criança, o que produz um desenvolvimento diferente em crianças diferentes, Teplov (1991) considera que os sentidos artísticos exigem uma percepção diferente do mundo, que vá além de seu aspecto cotidiano; que vá além do véu do hábito, que oculta o olhar, alcançando o aspecto real das coisas. Por isso, desenvolver artisticamente a criança significa ensiná-la a ver o mundo de maneira diferente, de um modo mais preciso e exato. Educando os sentidos, a arte ganha importância também para a educação em geral; cria os requisitos indispensáveis para um amplo e profundo conhecimento do mundo. 
O autor revela um posicionamento cognoscitivo sobre a arte, tomada como uma forma de conhecimento emotivo do mundo. E que também se constitui num dos meios mais eficazes de educação dos sentidos, o qual alarga a experiência emotiva do homem, "não só refletindo sentimentos íntimos que lhe são conhecidos, como também revelando sentimentos novos que antes lhe eram desconhecidos" (TEPLOV, 1991, p. 131).

A arte, vista como forma de conhecimento do mundo, partiria dos sentimentos e se desenvolveria como forma de "pensamento profundo e penetrante” (TEPLOV, 1991, p. 129). A percepção da arte partiria dos sentimentos, devendo avançar para além deles. Porém essa mesma percepção não seria possível sem "rendimento" (TEPLOV, 1991). Destaque-se aqui esse momento de "rendimento", o qual Teplov considera fundamental para a percepção da arte. Nesse trabalho considera-se "rendimento" como um termo correlato ao que em outros autores é denominado por catarse.

Em outro ponto do texto, Teplov estabelece uma diferenciação entre a leitura com o objetivo de conhecer o que se diz e o que sucederá depois, da leitura que é exigida pela literatura, que "vê e sente com o pensamento tudo o que há no problema, que transfere para o leitor a situação descrita, para o fazer viver nela" (TEPLOV, 1991, p. 128). Essa é a leitura que necessita de uma imaginação ativa, que pode e que necessita produzir identificação no contato com a obra; isto é, que necessita da "rendição". Em outras palavras, o autor, defende o entusiasmo como o primeiro momento necessário no estudo da poesia, por intermédio do qual a arte atingiria o coração primeiro e, depois, o cérebro (TEPLOV, 1991).

Isso implica que a percepção artística deve estar sempre orientada emotivamente, colocando a tarefa de conservar a orientação emotiva, por meio de uma progressiva diferenciação da atitude perante a arte, o seu conteúdo e suas técnicas (TEPLOV, 1991). O desenvolvimento estético se tornaria impossível se não se resolve o problema da subsistência da orientação emotiva. Além disso, para um verdadeiro desfrute e compreensão da arte seria preciso um estudo cada vez mais intenso de disciplinas que, muitas vezes, estáo à margem da arte. Dito de outro modo, a percepçáo da arte deve ser direta e emotiva, mas a capacidade para sua percepção não está diretamente dada. Para tanto, se fazem necessárias apropriaçóes anteriores, uma cultura desenvolvida tanto em sentido geral como em sentido especificamente estético. 
Para o autor, a atividade artística leva ao desenvolvimento de notáveis capacidades, combinando sensibilidade emotiva e autocontrole (TEPLOV, 1991). O que não se produz sem uma profunda implicação emotiva e sem a plena participação de todas as capacidades. A percepção artística favorece a capacidade de se assenhorear, ou seja, apoderar-se dos seus próprios sentimentos e controlá-los. A importância educativa fundamental da arte reside, assim, no fato de representar um modo de se ter acesso à vida interior, de gerar uma "perspectiva geral".

Para Teplov (1991, p. 133), "é importante que durante a dita experiência se criem atitudes e juízos morais, que assumem assim uma força incomparavelmente maior do que os juízos que são apenas comunicados e compreendidos". Esse juízo moral se desenvolveria com base na atividade interna, enquanto se "vive com o herói" uma história, por exemplo. Ressaltando-se que a possibilidade de criar um juízo moral depende dos elementos característicos de cada história. O que leva a pensar na responsabilidade que tem o criador da história, pois é quem define essas características, incorporando nos seus elementos formais suas próprias intençóes ideológicas.

Para Teplov (1991), qualquer obra de arte pode ter valor educativo se conseguir gerar identificação emotiva com o herói e suas açóes, fundindo num conjunto experiência moral e estética. A catarse, melhor dizendo, a identificação e o rendimento, seriam, portanto, fundamentais para gerar esses valores e mudanças de atitudes, determinando a personalidade dos indivíduos (TEPLOV, 1991).

\section{À guisa de conclusão}

Buscou-se nesse trabalho uma primeira aproximação às relaçóes entre arte, processo formativo e o fenômeno da catarse. Para tanto, selecionouse para análise autores que teorizaram sobre a educação estética e sobre a formação do indivíduo por meio da arte, servindo de aporte para a teoria marxista sobre o tema.

Visou-se com essa análise ilustrar as preocupaçôes que aludem direta ou indiretamente ao fenômeno da catarse na relação do sujeito com a arte, bem como sua importância e seu papel na formação da individualidade. 
Retomaram-se as proposiçóes marxistas por entender que podem lançar luz nas discussóes contemporâneas sobre a importância da educação estética para a formação do indivíduo e sobre a transmissão de valores cognoscitivos, morais e emocionais por intermédio da arte. Esses autores têm sido pouco divulgados, e a perspectiva materialista e dialética de seus estudos consiste num aporte teórico fundamental para evitar que se absolutize o papel da consciência no projeto de transformação social (como na perspectiva de alguns neohegelianos) ou que se retorne aos ideais subjetivistas da educação estética de Schiller (2002).

De comum a todas essas experiências, além de tentar contribuir na busca pela superação do capital, está a certeza de que a individualidade humana pode ser enriquecida e de que novas necessidades podem ser formadas pela apropriação das objetivaçóes humanas para-si, o que aponta para uma concepção histórico-social de individualidade.

De controverso, a posição em relação à catarse, é apontada tanto com potencial de alienação como de desalienação. Na dialética entre identificaçãodistanciamento, entretanto, claro está que a tradição marxista - por mais que autores diferentes enfatizem de maneira diversa os dois pólos da relação - afirma a indissociabilidade dos dois termos da relação, criticando a postura subjetivista radical das posiçóes filosóficas que defendem a fusão entre sujeito e objeto, na qual o objeto acaba por diluir-se nas projeçóes psíquicas do espectador.

Dessa forma, se em algumas propostas de educação estética da URSS a formação de uma personalidade plenamente desenvolvida aparecia na pauta do dia, dadas as transformaçóes sociais e a necessidade objetiva de superar a sociedade capitalista em todas as esferas da vida, é nesse mesmo contexto histórico que se devem buscar os elementos para a compreensão do estabelecimento do realismo socialista como proposta "oficial" de expressão artística. Afirmar que a identificação do espectador com o herói tinha papel fundamental para mobilizar as massas no sentido da construção da política oficial não pode ser feito sem considerar a política de Stálin (1947) de "socialismo em um só país" e o estabelecimento do primeiro plano quinquenal, que necessitava de ênfase substancial no sacrifício e comprometimento dos trabalhadores em nome da construçáo de um Estado proletário. 
Por sua vez, nas proposições estéticas de Adolfo Sánchez Vázquez, as principais contribuiçôes ao tema encontram-se nas sistematizaçôes em torno à dialética entre identificação e distanciamento. Sistematização que aparece de forma mais madura em suas últimas obras, mas que já aparecia anteriormente por meio da preocupação com a dialética entre alienação e desalienação quando escreve sobre a obra de José Revueltas (SÁNCHEZ VÁZQUEZ, 1996d).

A relação entre sujeito e objeto deve ser compreendida nessa perspectiva como uma unidade dialética na qual sujeito e objeto não se anulam nem se reduzem um ao outro. A identificação e o distanciamento entre sujeito e objeto constituem, então, a própria natureza dessa relação na situação estética.

Já a posição de B. M. Teplov (1991, p. 137) aproxima-se da perspectiva de Sánchez Vázquez (1996c) quanto à ideia de que para desempenhar uma função moral a arte deve antes "produzir uma impressão intensa", isto é, cumprir sua função estética. Entretanto, nesse autor aparece com maior ênfase o mecanismo de identificação e a possibilidade da mudança de atitudes e valores pela influência da arte. A identificação ganha importância tão significativa, que parece não sobrar espaço para o distanciamento que Sánchez Vázquez considera fundamental para o desenvolvimento da crítica. Para Sánchez Vázquez, pelo contrário, a incorporação das intençóes ideológicas do artista não são tão diretas como em Teplov. Ele diferencia a ideologia do autor da ideologia da obra, afirmando que podem inclusive estar em contradição.

O sentido artístico não nasce e não se desenvolve de uma forma autônoma na vida mental do homem, nem independentemente de outros aspectos da personalidade, como o aspecto moral e o intelectual. Isto implica na defesa, no plano educativo, de que a educação artística não deve separarse da educação geral, de maneira que todos os educadores considerem a educação artística como uma parte essencial e integral de seu trabalho.

Essas aproximaçóes e afastamentos entre as teorias do campo marxista, antes de serem escamoteadas, devem ser explicitadas e discutidas, na tentativa de fazer avançar a pedagogia teórica e a psicologia da arte. Pois explicitar o debate teórico em torno da categoria catarse é apenas um dos momentos a serem vencidos, restando ainda uma série de desafios relacionados, por exemplo, com a prática da educação estética no ambiente escolar e como lidar 
com o desenvolvimento do juízo estético e a manutenção da possibilidade da catarse - no caso de se considerar sua importância.

Por fim, cabe relembrar que a arte como parte das esferas de objetivação genérica para-si, sendo gerada no interior das relações de dominação, tem tanto uma função humanizadora quanto uma função na reprodução da alienação (DUARTE, 1993). Portanto, não é o simples contato com a obra de arte que instaura um processo formativo para-si (de desenvolvimento de uma individualidade para-si). Sob relações de dominação, mesmo que o indivíduo se desenvolva no sentido de uma individualidade para-si, ele não está isento de contribuir com a reprodução da alienação por meio do resultado concreto de suas ações. Ou seja, é impossível a superação da alienação apenas no plano individual. Essa só pode ocorrer por um processo coletivo de superação das relaçóes objetivas que a determinam. É nesse sentido que as propostas analisadas podem contribuir, pois buscam aliar a transformação da individualidade com processos reais de transformação das relaçôes sociais.

\section{Notas}

1 Como se pode constatar pelo texto de Castanho (2005), atualmente tem-se optado também pela expressão "arte educação". Assinala-se aqui que essa opção pode estar sendo feita na tentativa de fugir ao debate e produzir consenso, opção que longe de fazer avançar o debate na área, tende a escamotear as grandes diferenças epistemológicas postas na questão.

2 Na referência do texto que utilizaremos para essa análise, a tradução portuguesa traz o nome como R. M. Teplov. Adotaremos a utilização mais usual e que é seguida por Shuare (1990), a saber, B. M. Teplov (referindo-se à Boris Mikhailovich Teplov).

3 Sabe-se que nesses autores a questão do papel da catarse não ganha contornos tão precisos como em Lukács e em Vigotski, pensadores nos quais se encontra uma posição conceitualmente melhor definida em relação à catarse e sua função no processo de formação humana, como parte de uma reflexão estruturada sobre a formação do indivíduo. $\mathrm{Na}$ pesquisa de pós-graduação que ora se realiza, sobre o papel da catarse 
para a formação humana na psicologia da arte de Vigotski e na estética de Lukács, alem da revisão dos autores aqui citados, têm se considerado também a obra do cineasta Tomaz Gutiérrez Alea, que se propóe a sintetizar as posiçóes de Sergei Eisentein e de Bertold Brecht relacionadas à catarse.

4 Rossler (2003) considera a identificação como um processo de vinculação afetiva entre um sujeito e um objeto, o qual ocorre quando algo desse objeto remete às motivaçóes, às crenças, aos desejos, aos valores e aos interesses particulares daquele sujeito. Embora a vinculação afetiva profunda seja um processo "saudável", também estaria na base dos mecanismos psicológicos da sedução, entendidos como fenômeno de alienação, isto é, como vivência alienada dos afetos, caso essa vinculação se dê a partir de um processo de identificação espontânea.

5 Utiliza-se aqui a edição de 1982 das Edições Progresso.

6 Note-se que se considera nesses escritos a concepção leninista de ideologia que, grosso modo, pode ser tomada como conjunto de ideias que está ligado a uma classe social. Essa concepção difere da concepção marxiana de ideologia como "falsa consciência", como possibilidade de falseamento do real.

\section{REFERÊNCIAS}

CASTANHO, M. E. L. M. Função educacional da arte. Educação temática digital, Campinas, v. 6, n. 2, p. 85-98, 2005.

DUARTE, N. A individualidade para-si. Campinas: Autores associados, 1993.

GRAMSCI, A. Literatura e vida nacional. Rio de Janeiro: Civilização brasileira, 1978.

HEGEL, G. W. F. Cursos de estética I. São Paulo: Edusp, 2001.

IULDÁCHEV, L. G. A cultura estética da sociedade socialista. In: OVSIÁNNIKOV, M. F. et al. Fundamentos da estética marxista-leninista. Moscou: Ediçóes Progresso, 1982. p. 186-213. 
LENIN, V. I. La literatura y el arte. Moscou: Editorial Progresso, 1979.

MARX, K. Manuscritos econômico-filosóficos. São Paulo: Boitempo Editorial, 2006.

MÉSZÁROS, I. A educação para além do capital. São Paulo: Boitempo, 2008.

MÉSZÁROS, I. Aspectos estéticos. In: MÉSZÁROS, I. A teoria da alienação em Marx. São Paulo: Boitempo, 2006. p. 173-193.

MORAES, B.; JIMENEZ, S. Notas sobre a questão da individualidade humana em Marx: um convite à pesquisa. Revista Eletrônica Arma da Crítica, Fortaleza, v. 1, n. 1, p. 14-23, 2009.

PLEKHANOV, G. A arte e a vida social. Lisboa: Moraes editores, 1977.

ROSSLER, J. H. Sedução e modismo na educação: processos de alienação na difusão do ideário construtivista. 2003. 291 f. Tese (Doutorado em educação)-Faculdade de Ciências e Letras, Universidade Estadual Paulista, Araraquara, 2003.

SÁNCHEZ VÁZQUEZ, A. La estética terrenal de José Revuletas. In: - Cuestiones estéticas y artísticas contemporáneas. México: Fondo de Cultura Económica, 1996d. p. 68-81.

SÁNCHEZ VÁZQUEZ, A. Prolegómenos a una teoría de la educación estética. In: . Cuestiones estéticas y artísticas contemporáneas.

México: Fondo de Cultura Económica, 1996c. p. 95-106.

SÁNCHEZ VÁZQUEZ, A. Trayectoria de mi pensamiento estético. In: . Cuestiones estéticas y artísticas contemporáneas. México: Fondo de Cultura Económica, 1996b. p. 107-114.

SÁNCHEZ VÁZQUEZ, A. Lunacharsky y las aporías dela arte y la revolución. In: . Cuestiones estéticas y artísticas contemporáneas.

México: Fondo de Cultura Económica, 1996a. p. 152-168.

SÁNCHEZ VÁZQUEZ, A. Convite à estética. Rio de Janeiro: Civilização Brasileira, 1999.

SCHILLER, F. A educação estética do homem. São Paulo: Iluminuras, 2002. 
SHUARE, M. La psicología soviética tal como yo la veo. Moscou:

Progresso, 1990.

STÁLIN, J. V. Resposta ao camarada Ivanov. Problemas: Revista Mensal de Cultura Política, Dezembro de 1947.

TEPLOV, R. M. Aspectos psicológicos da educação artística. In: LURIA et al. Psicologia e pedagogia II. Lisboa: Editorial estampa, 1991. p. 123153. 


\section{Marxists proposals of aesthetic education: approaches and distancing towards the catharsis phenomenon}

\section{Abstract}

The present paper aimed to ponder about the aesthetic education role on forming individuals through theories that stake on the art's possibility of starting a reality transformation contributing to end the alienation. The aesthetic education theories from the Marxists L. G. Iuldáchev, B. M. Teplov, and A. Sánchez Vázquez were analyzed. On the scope here proposed, it was aimed to demonstrate that although the three authors start from a social-historical individuality concept, their conceptions differ on the catharsis approach. On the dialetics of subject's identifying or distancing with the artistic object, the authors' emphasis on one or another moment during the relation ends up marking it's relation around the catharsis. While in Iuldachév and Teplov one can say that the identification moment is highlighted, Sánchez Vázquez wants, through the concept of aesthetic situation, to recover the importance of distancing in this relation. By studying these author theories it can be possible to bring the reflections about aesthetic education, as to assist, with its materialistic and dialetic perspective to criticize the studies that absolutize
Propuestas marxistas de educación estética: a c e r c a m i e n to s y alejamientos alrededor del fenómeno de la catarsis

\section{Resumen}

El presente trabajo intenta hacer una reflexión acerca del papel de la educación estética en la formación del individuo, a partir de teorías que aseveran la posibilidad del arte impulsar la transformación sobre la realidad y contribuir para la superación de la alienación. Se analizaron las teorías de educación estética de los autores marxistas L. G. Iuldáchev, B. M. Teplov y A. Sánchez Vázquez. En el recorte aquí propuesto, se ha buscado demostrar que, aunque los tres autores parten de una concepción histórico-social de la individualidad, sus formulaciones son distintas en lo referente al abordaje del fenómeno de la catarsis. En la dialéctica entre identificación y alejamiento del sujeto con el objeto artístico, el énfasis de los autores sobre uno u otro momento de la relación termina por marcar su posición acerca de dicho fenómeno. Mientras que en Iuldachév y en Teplov se puede decir que se pone en relieve el momento de la identificación, Sánchez Vázquez busca con el concepto de situación estética recuperar la importancia del alejamiento en esa relación. Se cree que estudiar las formulaciones de esos teóricos puede 
the role of conscience on the social iluminar las reflexiones actuales sobre transformation project.

Keywords: Aesthetic. Education. con su perspectiva materialista y Marxism. Catharsis. dialéctica, la crítica a los estudios que absolutizan el papel de la conciencia en el proyecto de transformación social. Palabras clave: Educación Estética. Marxismo. Catarsis.

\section{Vitor Marcel Schühli}

E-mail: vitorschuhli@yahoo.com.br

\section{Joáo Henrique Rossler}

E-mail: joheross@yahoo.com.br

Recebido em: 14/12/2010

Versão final recebida em: 26/10/2011

Aprovado em: 10/11/2011 